\title{
The fascinating diatom frustule-can it play a role for attenuation of UV radiation?
}

Ellegaard, Marianne; Lenau, Torben Anker; Lundholm, Nina; Maibohm, Christian; Friis, Søren Michael Mørk; Rottwitt, Karsten; Su, Yanyan

Published in:

Journal of Applied Phycology

Link to article, DOI:

10.1007/s10811-016-0893-5

Publication date:

2016

Document Version

Peer reviewed version

Link back to DTU Orbit

Citation (APA):

Ellegaard, M., Lenau, T. A., Lundholm, N., Maibohm, C., Friis, S. M. M., Rottwitt, K., \& Su, Y. (2016). The fascinating diatom frustule-can it play a role for attenuation of UV radiation? Journal of Applied Phycology, 28(6), 3295-3306. https://doi.org/10.1007/s10811-016-0893-5

\section{General rights}

Copyright and moral rights for the publications made accessible in the public portal are retained by the authors and/or other copyright owners and it is a condition of accessing publications that users recognise and abide by the legal requirements associated with these rights.

- Users may download and print one copy of any publication from the public portal for the purpose of private study or research.

- You may not further distribute the material or use it for any profit-making activity or commercial gain

- You may freely distribute the URL identifying the publication in the public portal 
The fascinating diatom frustule - can it play a role for attenuation of UV radiation?

Marianne Ellegaard ${ }^{1}$, Torben Lenau ${ }^{2}$, Nina Lundholm ${ }^{3}$, Christian Maibohm ${ }^{4}$, Søren Michael Mørk Friis ${ }^{4}$, Karsten Rottwitt ${ }^{4}$, Yanyan $\mathrm{Su}^{1}$

${ }^{1}$ Department of Plant and Environmental Sciences, University of Copenhagen, Thorvaldsensvej 40, 1871 Frederiksberg, Denmark. Corresponding author Marianne Ellegaard me@plen.ku.dk; phone: +45 35320024

${ }^{2}$ Department of Mechanical Engineering, Technical University of Denmark, Produktionstorvet, Building 426,2800 Kongens Lyngby, Denmark

${ }^{3}$ The Natural History Museum of Denmark, University of Copenhagen, Sølvgade 83S, DK-1307 Copenhagen K, Denmark

${ }^{4}$ Department of Photonics Engineering, Technical University of Denmark, Ørsteds Plads 343, 2800 Kongens Lyngby, Denmark

Key words: UV protection, photonics, photobiology, nano-patterning, diatom

\section{Reference:}

Ellegaard, M., Lenau, T. A., Lundholm, N., Maibohm, C., Friis, S. M. M., Rottwitt, K., \& Su, Y. (2016). The fascinating diatom frustule - can it play a role for attenuation of UV radiation? Journal of Applied Phycology. doi:10.1007/s10811-016-0893-5 


\begin{abstract}
Diatoms are ubiquitous organisms in aquatic environments and are estimated to be responsible for $20-25 \%$ of the total global primary production. A unique feature of diatoms is the silica wall, called the frustule. The frustule is characterized by species specific intricate nano-patterning in the same size range as wavelengths of visible and ultraviolet (UV) light. This has prompted research into the possible role of the frustule in mediating light for the diatoms' photosynthesis as well as into possible photonic applications of the diatom frustule. One of the possible biological roles, as well as area of potential application, is UV protection. In this review we explore the possible adaptive value of the silica frustule with focus on research on the effect of UV light on diatoms. We also explore the possible effect of the frustules on UV light, from a theoretical, biological and an applied perspective, including recent experimental data on UV transmission of diatom frustules.
\end{abstract}

\title{
Introduction
}

The diatoms are unique among algae in that the cell is completely enclosed in a continuous silica-based cover, the frustule. The frustule is as a rule built more or less like a petri dish, with an inner and outer valve, connected by girdle bands (Fig. 1). Diatoms are also special among eukaryotic microalgae as due to the frustule they have a fixed cell shape, and they lack flagella in the vegetative stages. Diatoms are ubiquitous organisms in aquatic environments and can be dominant primary producers in all aquatic habitats, including ice. They are thus estimated to be responsible for $20-25 \%$ of the total global primary production (Nelson et al. 1995). Diatom species diversity is far from discovered at present. Some 10,000 species have been formally described, but it is estimated that the real number of species is 10-20 times higher (Guiry 2012). Traditionally, species descriptions have been based on details in the intricate nanoscale pattern of holes in the frustule and each species thus has its own distinct pattern which is reproduced at cell division. While benthic diatoms have evolved a specialized mode of movement via a slit through the frustule called the raphe, planktic diatoms are non-motile and are therefore dependent on buoyancy and water movement to stay suspended in the photic zone. As the frustule is generally denser than both seawater and freshwater, it would seem to be an impediment to photosynthetic organisms dependent on staying up in the photic zone. Possible adaptive roles of the diatom frustule have therefore been explored, from the point of view that the frustule must give adaptive advantages that off-set this seeming disadvantage. We will focus on the evidence for a role in protecting the diatom cell from ultraviolet radiation (UV) damage. That the frustule interacts with light is clear already when studying frustules under the light microscope (Fig. 2b). This, and the fact that some frustules, such as that shown in Fig. 2b, look very similar to a very thin slice of a photonic crystal fiber or micro-structured optical fiber, has prompted intensive research into possible photonic applications of diatom frustule. In this review we will focus on potential for UV protective applications.

\section{Review}

The suggested adaptive functions of the diatom frustule

The diatom frustule has been suggested to be a by-product of other adaptations rather than giving an adaptive advantage per se. Thus some authors state that it is metabolically cheap to produce relative to other types of cell covering (only $2 \%$ of the energy budget of the cell; Raven 1983) although other authors 
question this (Finkel and Kotrc 2010; Lavoie et al 2016). Medlin (2002) put forward the hypothesis that, because silica metabolism plays an important role in resisting aging, the silica frustule is mainly a byproduct of this. Other adaptive advantages have been suggested, including a deliberate increase of the density of cells, altering sinking rate via spine development, resisting turgor changes and resistance to parasites (reviewed by Raven and Waite 2004). However, the suggestions which have received most support are: 1 . defense against predation, 2 . proton/pH buffering and 3. modulation of light within the cell. To test the first hypothesis (defense against predation) Hamm et al. (2003) performed a study where they tested the strength of differently shaped frustules (three species), using glass micro needles to press the cell and measuring the force necessary to break single cells. They conclude that all three shapes of cells tested are remarkably strong due to their architecture and the material properties of the silica. The second hypothesis, pH buffering, has received support from both laboratory testing of the efficacy of diatom biosilica as a pH buffer (Milligan and Morel 2002) and from theories linking major events within the evolutionary history of diatoms to changes in atmospheric $\mathrm{CO}_{2}$ levels, and thereby $\mathrm{pH}$ in aquatic systems (e.g. Armbrust 2009). A third suite of hypotheses deal with different aspects of controlling the light regime within the diatom cell (Fuhrman et al. 2004), by functioning as a photonic crystal (Fuhrman et al. 2004), by scattering visible light (Raven and Waite 2004) or by reflecting, absorbing or scattering light in the UV range (below 380 nm; Davidson et al. 1994; Raven and Waite 2004). In this review we focus on the possible role of frustules in modulating UV light, as well as discussing which characteristics of the diatom frustule are central to the photonic effects.

\section{Photonic applications or diatom biology?}

When discussing potential photonic utilizations of diatom frustules, the light environment that diatoms are adapted to under natural conditions should be taken into account. When light enters water, it becomes partially polarized and is absorbed more strongly than in air in a wavelength dependent way. Red, orange and yellow are quickly absorbed by the water, only penetrating meters below the surface while blue light is not strongly absorbed by water and can penetrate much deeper, depending on the concentration of dissolved matter and particles (Depauw et al. 2012; see also Fig. 2). A couple of meters below the surface almost half of the integrated light intensity will be in the UV spectral region, i.e. below $400 \mathrm{~nm}$, compared to only about $3 \%$ at ground level (Johnsen and Sosik 2004). Diatoms thus live in a light environment dominated by UV and blue light, supporting the idea that the frustule may play a role in UV light protection. As most studies aimed at characterizing the photonic properties of diatom frustules and elucidating their industrial potential are done on rinsed frustules, the organic material in the cell content is taken into account in neither measurements nor simulations. Further, most of these studies are performed or simulated in air, contrary to the aquatic natural habitat of the diatoms (although there are exceptions, e.g. De Tommasi et al. 2010; Di Caprio et al. 2014; Hsu et al. 2012; LeDuff et al. 2016). Therefore the calculated effects of these experiments and simulations apply to the frustule, and for use in applications of rinsed frustules, but cannot give full biological answers as to how the living diatoms benefit by the interactions between the frustule and light. These differences between measurements on rinsed (and often separated) frustules and the diatom in its natural habitat are summarized in Fig. 2.

Another aspect to be considered is the orientation of the frustule. Under natural conditions, in aquatic planktic environments, light will hit the diatom cell from the outside of the frustule (the convex side), but some of the light may also be affected by the (concave) inside of the opposite valve as it passes through the 
cell. Under experimental conditions to test the effect of the frustule nano-pattern on incident light, the frustules will typically have been cleaned of organic material (cell content and any organic covering) and the frustule will be separated into its parts - the two valves and the girdle bands (see Fig. 1). Typically, measurements (and simulations) have been done on a single valve. It is not always clear from which direction the light is hitting the valve, and the question is how the orientation of the valve affects the measurements. Do the photonic properties differ depending on whether the incident light hits the valve from what was the outside or the inside of the cell? For measurements on a layer of frustules, another question is whether is there a pattern to how a single valve will normally fall when in a drop of water or another liquid matrix. Based on the (sparse) literature to date on this, and on our own unpublished data, the answer to both these questions appears to be yes. Preliminary results indicate that in a drop of liquid the valves fall approximately one third more often with the inside up (Gössling et al. pers. comm.). This can, however, be controlled as shown by Wang et al. (2012), where the valves are made to all face in the same direction by suspension and subsequently extracting the liquid. We have observed differences in our measurements with regard to interference points, dependent on the way the valves are facing (unpublished data). This is in good agreement with findings by Romann et al. (2015), where no interference points (see e.g. Maibohm et al. 2015a) are observed when the valve is facing with the outside towards the microscope in transmission experiments.

\section{Effects of UV-light}

UV light is in general detrimental to living organisms (although near UV light may be photosynthetically active; Xu and Gao 2010) as well as many man-made materials; the shorter the wavelength, the more damaging (with the effect further enhanced by resonant behavior at specific wavelengths from possible absorption peaks). Effects of increased UV levels on living diatoms have been studied in a changed global climate scenario since human-induced reductions in the ozone layer of the stratosphere were reported decades ago (e.g. Wu et al. 2014). Polar regions (receiving increasing UV light) as well as mountain habitats (naturally high UV radiation) have been the preferred habitats for UV research on algae. As most UV radiation is not photosynthetically active, cell strategies would thus be expected to be either to avoid or tolerate UV radiation (Holzinger and Lütz 2006). A UV-induced effect is dependent on the level of UV, the duration of the exposure, the spectral composition of the light in the UV range, the sensitivity of the organism(s) investigated, physiological status, ambient nutrient conditions and temperature (Buma et al. 1996; Cullen and Lesser 1991; Litchman and Neale 2005; Hessen et al. 2012). UV radiation harms cells through absorption by nucleic acids and proteins and hence inhibiting DNA translation, replication and transcription (Buma et al. 1995; Holzinger and Lütz 2006). But comparisons among studies of UV effects on algae are hampered by difficulties in comparing radiation conditions which cannot be recalculated and thus compared (Holzinger and Lütz 2006). Thus, in future studies of the possible effects of the frustule on UV light, it would be advantageous to standardize the method of registering UV intensity and wavelength.

A decrease in photosynthesis has been the most prominent UV effect in algae (Waring et al. 2006; Holzinger and Lütz 2006), and decreases in biomass and/or growth rate of diatoms exposed to UV radiation are commonly reported (e.g. Reizopoulou et al. 2000; Nahon et al. 2010), but the effect and the recovery capability after UV exposures apparently vary among species (Buma et al. 1996), as species composition in exposed communities are reported to change with time (Reizopoulou et al. 2000). This agrees with varying effects of UV among cultured diatom species both with regard to response and sensitivity to UV (Karentz et 
al. 1991; Davidson et al. 1994; Waring et al. 2006; Hessen et al. 2012; Scholz et al. 2014), even among species within a genus (Hargraves et al. 1993). This has raised speculations as to why differences in UVeffects vary more in diatoms than in other algal groups where the responses can often be correlated to cell size due to size related effects on self-shading and UV-absorbing compounds (Waring et al. 2006 and references herein). One possible explanation could be that this difference is due to species specific differences in the pattern of holes or other characteristics of the frustule.

Chronic UV-B exposure on diatoms has often been related to increases in cell volume (due to a decoupling between cell growth and cell division) and decreases in growth rates (Karentz et al. 1991; Buma et al. 1995; 1996; Holzinger and Lütz 2006 and references therein; Nahon et al. 2010; Scholz et al. 2014). An increase in number of chloroplasts and thus in cellular pigment content has been observed in some diatoms (Buma et al. 1996), whereas others have found a reduction in pigmentation (Lohmann et al. 1998). Others again showed an increase in potential photoprotective pigments like diadinoxanthin and diatoxanthin (Döhler 1995; Leu et al. 2006). In a study on long-term acclimation, several diatom species acclimated by changing photosynthesis related pigments, whereas one species, Amphora coffeaeformis, lacked these pigment changes (Rech et al. 2005). It has been suggested that UV absorbing compounds, mycosporine-like amino acids (MAAs), chemically bound to the diatom frustule provide diatoms with UV protecting properties (Ingalls et al. 2010), and they explain a lack of increase in MMAs in diatoms in response to UV, in contrast to flagellates (Davidson et al. 1994), to be related to the tight association with the frustule (Ingalls et al. 2010). This hypothesis is supported by high MAA content in two centric diatom species related to lack of UV effect on photosynthesis, as opposed to lower MAA concentrations in two pennate diatoms affected by UV (Helbling et al. 1996).

Nitrate-limitation increases the sensitivity of diatoms to UV light due to a decrease in photochemical quantum yield (Cullen and Lesser 1991; Scholz et al. 2014). Moreover, it has been reported that the sensitivity of diatoms to UV radiation could be increased by elevated $\mathrm{CO}_{2}$ due to a reduction in relative electron transport rate (Wu et al. 2012). An additional stress for diatoms has been observed under certain salinity conditions combined with UV radiation, and this combined effect is species-dependent (Döhler 1984; Rijstenbil 2005).

In spite of the reported effects of UV radiation, some studies find no effect of UV on diatoms, or less effect than on flagellates (Villafane et al. 1995; Vernet 2000; Litchman and Neale 2005; Guihéneuf et al. 2010; Hessen et al. 2012: Wu et al. 2012). So far no explanation has been found for this difference. We hypothesize that it is the diatom frustule and its characteristics which reflect or absorb the UV and therefore protect the diatom cells against UV. This is supported e.g. by observations of diatoms not responding to UV with a change in fatty acid composition or having very low amounts of MMAs in contrast to many other microalgae like dinoflagellates (Jeffrey et al. 1999, Guihéneuf et al. 2010 and references herein). Also Jeffrey et al (1994) underlined that the survival of diatoms exposed to UV did not correlate with absorption by e.g. pigments.

\section{Potential industrial applications of diatom frustules}

Similar to other algal groups, potential industrial applications of diatoms include biofuels (e.g. Levithan et al. 2014), bioplastics (Hempel et al. 2011) and other uses of the organic cell contents (Bozart et al. 2009). Unique among the algae, however, is the additional potential for applications of inorganic material: the 
silica frustule. Geological deposits rich in prehistoric diatom remains, called diatomaceous earth, are already industrially exploited for e.g. filtering (Parkinson and Gordon 1999).

In recent decades, diatom frustules have been the focal point for intense optical studies due to their inherent strong interaction with light (including UV radiation) and potential industrial uses of specific characteristics. The ideas for potential applications for the silica frustule include photonic crystals (Fuhrman et al. 2004, Yamanake et al. 2008; de Stefano et al. 2009), chemical sensors (de Stefano et al. 2009), microlenses (de Stefano et al. 2007a), enhanced light harvesting in solar cells (Ottesen 2011), light focusing capabilities and applications of this, such as optical switches (De Tommasi et al. 2010; Maibohm et al.

2015a; Ferrara et al. 2014). Due to the destructive effects of UV light on living organisms and many types of materials, and due to the unwanted effects associated with many types of UV protection there is great interest in finding novel means of UV protection without deleterious aspects. UV protection is important e.g. to protect polymers from deterioration when exposed to sunlight and for the protection of human skin in sun lotions. The potential advantage of using diatoms as UV-filters would be that it may be possible to selectively reflect or absorb certain wavelengths. Such a filter therefore has the potential not to impact the color of the material. It would for instance be possible to make durable transparent polymers and lacquers with lasting properties in sunlight. The most effective UV-filter used for polymers is carbon black which absorbs not only UV but also other wavelengths of light and therefore appear black (Coleman 2011). There are other additives to polymers that prevent degradation from UV-light including Hindered Amine Light Stabilizers (HALS) that work by trapping free radicals formed during photo-oxidation of the polymer (Gijsman 2011) thus extending the lifetime of the polymer. Sun lotions typically protects the skin from both UVA (400-320 nm) and UVB (320-290 nm) light.

\section{Parameters central to photonic applications of diatom frustules}

For application purposes it is not necessary to know the full interaction between the light and the frustule. It is enough to know the effects which are important to the application needed.

Development of sophisticated methods and equipment, which have revealed material composition and three dimensional (3D) structure, have strengthened the potential for applications of the frustule. When light interacts with the frustule, some effects can easily be observed in a light microscope (Fig. 2b, c). The intricate, semitransparent, nano-structured frustule causes light to be transmitted or multiple reflected from the different interfaces giving rise to phase shifts as well as frequency dependent constructive and destructive interference (Parker and Townlee 2007; Gordon et al. 2009; Maibohm et al. 2015a, b). In addition to these easily observed optical phenomena more sophisticated optical effects have been theorized, i.e. wave-guiding and band-gaps (Fuhrmann et al. 2004). If diatom frustules are to be used in industrial applications we need to determine which aspects are central for the desired application. Although there is huge morphological variation among the individual species of diatoms, this review discuss common traits as well as identify differences (see e.g. Maibohm et al. 2015b) which can be exploited for application purposes.

\section{Structural properties of the diatom frustule}

Diatoms can roughly be divided into two different groups based on their valve symmetry, the centrics (radially symmetrical) and the pennates (bilaterally symmetrical). For both forms, the valve is a very 
complex 3D structure, as seen in Fig. 1 and in graphene reproductions (Pan et al. 2014). The size features of nanopattern of the valve vary from species to species and are in the order of wavelengths of UV-C to near infrared light. This includes photosynthetically active radiation (PAR) $(400-700 \mathrm{~nm})$, indicating that PAR light will be strongly influenced when it interacts with the frustule. This is seen when light in the PAR wavelength range is transmitted through the frustule; the pore structure interacts with the light and creates a wavelength dependent interference pattern (De Tommasi et al. 2010; Maibohm et al. 2015a). The structure also interacts with the light in a way that it redirects light towards the cell interior even when light is striking the frustule at another angle than normal incidence (Maibohm et al. 2015c).

\section{Material properties of the diatom frustule}

The frustule material is predominantly silica precipitated by diatoms from silicic acid with species-specific size and pattern of holes. The specific silica structure of the frustule is usual characterized as amorphous hydrated silica but there have also been indications from X-ray diffraction studies that part of the frustule could be composed of $\alpha$-quartz with a grain size of few tenths of micrometers (Goswami et al. 2012). In addition to this, trace impurities such as aluminum, magnesium, iron and titanium can be part of the frustule material (Butcher et al. 2005). These trace impurities are taken up from the water environment and incorporated into the frustule by the diatom cell.

\section{Simulation of light interaction with the frustule structure}

The transmission of light through a diatom valve can be simulated using Maxwell's equations, which govern the propagating electromagnetic field. A geometrical optics approach is insufficient because, as described above, the structures of the valve are on the same scale as the wavelength of visible and UV light; hence, diffraction plays an important role, and some interference patterns are readily observed already under a normal light microscope (Fig. 2b, c). Accurate numerical modelling of the three-dimensionally structured valve requires many computational resources so it is desirable to simplify the model of the valve and focus on few of its features. For such simulations, the valve is generally assumed to be a plane glass surface with a pattern of air holes, which resembles the larger holes on one side of the valve as seen in Fig. $2 \mathrm{~b}$. Some studies have also modelled the other plane of the valve, either including the more intricate hole structure (De Tommasi et al. 2010), or as a homogeneous surface absent of holes (Yamanaka et al. 2008). In the literature, two different schemes of simulation approaches have been pursued: one considers the transmission of light through the plane of the valve where light passes through the holes, and the silica walls are considered opaque or partly transparent; the edges of the holes are consequently responsible for diffraction of the propagating beam. The theory behind this and a numerical algorithm to carry out this approach was described by Delen et al. (1998). The aim of this approach is to explain the lens-less light focusing observed by De Stefano et al. (2007a), where it was found that the array of larger holes in the valve plays a critical role in understanding the complex diffraction pattern behind the valve; the smaller holes on the other plane of the valve (in the cribrum) were ignored in that model. Later, the same approach, including the smaller holes however, was used to predict that , for visible light, multiple focus points are found as close as 100-200 $\mu \mathrm{m}$ from the plane of the valve, but that no such focusing is found for shorter wavelengths in the UV regime (De Tommasi et al. 2010). While the latter prediction remains unconfirmed by experimental investigations, a recent study showed excellent agreement between experimental data and theory and without the smaller holes in the visible regime (Maibohm et al. 2015a), thus validating this numerical approach. 
The other common approach found in the literature is the propagation of light in the plane of the valve as first presented by Fuhrmann et al. (2004); it is shown that the valve may act as a waveguide in which the optical properties are determined by the periodic structure of the large air holes in the direction of propagation. Such a structure may lead to photonic band gaps (PBG; see later) depending on the parameters of the specific structure and the refractive index contrast between the valve material and the materials in the holes (air or water). The study by Fuhrmann et al. (2004) and a later study by Kieu et al. (2014) show no PBG for accurate models of diatom frustules. On the other hand, it has been shown that if the refractive index of the frustule is increased to 2.4 (which may be realized by material substitution as mentioned below) a full PBG is found at a wavelength of $2.2 \mu \mathrm{m}$ (De Stefano et al. 2009). This suggests that the frustule may find use in industry as a new optical chemical sensor (De Stefano et al. 2009).

Besides the discovery of PBGs, the study of photonic bands gives more information about the interaction of light with the diatom frustule: in another study, strong absorption was found in the blue region of visible light and part of the UVA region by transmitting light through a frustule (Yamanaka et al. 2008). Simulations of the photonic bands of an accurate model of the frustule showed that a strong interaction between the frustule and light of wavelengths in the shorter part of the visible spectrum.

\section{Photoluminescence}

Porous silica, one of the main constituent frustule materials, is known to emit photoluminescence (PL) in the visible spectral region when irradiated with UV-light (Cullis et al. 1997). The diatom frustules can also exhibit PL with one or more spectral peaks which can be more or less pronounced (Butcher et al. 2003, 2005; de Stefano et al. 2007b; Mazumder et al. 2010; Viji et al. 2014). Thus researchers have for excitation used wavelengths of $325 \mathrm{~nm}$, with emission at 539.4nm (de Stefano et al. 2009) and 300, 370 and $380-$ all with emission at 440nm (Mazumder et al. 2010; Viji et al. 2014). Experiments show great differences in PL activity among diatom species and even among diatoms from same the culture, from no PL activity to intensities measurable with the naked eye (Butcher 2005; Maibohm et al. 2015c). Our own experiments with cultivated diatoms, from the same culture, show low PL activity or sometimes no PL at all; underlining that the uptake of minerals from the surroundings and other influencing parameters to the PL activity are of importance on the individual cell level (Maibohm et al. 2015c). For application purposes the local environment of the cleaned frustules has a huge influence. An oxygen-containing atmosphere works as a fast quencher of PL activity while a controlled atmosphere, as in a ultrahigh vacuum system, the frustule PL activity has been shown to act as a gas sensor by binding various types of gasses and thereby either quench or enhance the PL activity (de Stefano et al. 2007b). The position and shape of the PL spectrum is dependent on the UV excitation wavelength, and the presence of multiple peaks, i.e. multiple de-excitation pathways, is attributed to non-uniform crystallite size, trapping states and impurities in the frustules (Goswami et al. 2012). The PL spectrum is dominated by peaks from the amorphous silica, but it is also affected by the small amounts of trace impurities in the frustule. Uptake of trace elements will change the absorption and transmission characteristics of the frustule again, the degree depending on the element and the concentration of it. The natural amount of trace impurities varies, depending on the habitat, and the trace impurities can either be deposited in the frustule by the cell or adsorbed to the frustule directly from the environment (de Jonge et al. 2010). The PL can also be affected by adsorption of material which quenches, enhances or alters the PL spectra (de Stefano et al. 2007b; Gale et al. 2009; Viji et al. 2014). Changes in PL spectra have been used as a novel type of gas sensor where binding absorption of molecules 
on the frustules leads to a measureable change (de Stefano et al. 2007b). Metal doped frustules can also be stimulated by an electric current and subsequently emit electroluminescence (Jeffryes et al. 2008).

\section{Photonic bandgaps, wave-guiding and Bragg scattering}

These three photonic phenomena are of central relevance and interest for studying diatom frustules, particularly with regard to the possibility for using diatom frustules to selectively screen out specific wavelengths of light.

Photonic crystals are periodic structures that photons of certain wavelengths cannot propagate through. The non-propagating wavelength or usual the bandwidth of non-propagating wavelengths constitutes the so-called photonic bandgap (PBG). Formation of a PBG in a structure can be viewed as the synergetic interplay between the macroscopic Bragg scattering resonance (which stems from the periodic structure of alternating material and creates stop gaps when the period of the structure coincides with an integer number of half the wavelength of the light) and the microscopic scattering resonance, which stems from the single unit cell of the structure, called the Brillouin zone and is related to how the structure is ordered. In the case of the diatom frustule, the macroscopic scattering would be from the holes (consisting of water or, when cleaned, air) alternating with the silica walls. The microscopic scattering would be from how the holes are arranged in the frustule, for instance a hexagonal structure. If both the macroscopic and microscopic resonance occurs at the same wavelength formation of a PBG is greatly enhanced. The wavelength or rather the bandwidth over which light is not transmitted depends also on the difference in refractive index between the two materials of the microstructure. In general, the larger the difference in refractive index, the easier it is to obtain a PBG. The center wavelength and the bandwidth of the PBG are therefore determined by the macroscopic periodicity (i.e. the distance between the holes and the size of the holes), microscopic symmetry (how the holes are arranged compared to each other), material composition and polarization of the light. The propagation direction of the light in the above section is presumed to be in the plane of the alternating structures and therefore light needs to be coupled to (or redirected to) the structure in this plane. The complexity of the photonic crystal, and thereby the relation between the before mentioned parameters increases with the need of multiple propagation directions which includes a PBG. Wavelengths included in the PBG and in the propagation direction of the PBG is reflected from the structure and many applications benefit from the strong wavelength-dependent propagation of light. Many of these applications do not even require that the periodically modulated material exhibit all properties of photonic crystals but only that, light is reflected differently depending on its wavelength, i.e. the macroscopic Bragg scattering. This effect can be seen in the colors of certain butterflies where the scattering is wavelength dependent and therefore the spectral response also depends on the observer.

Diatom walls have repeated nanostructures (Figs 1, 2b) in the relevant size range of PAR and UV light and have been shown to have certain characteristics of photonic crystals. The ordered structure of the holes has indicated the possibility of photonic band gaps when light is propagating in the valve plane. This has been calculated for both valves and girdle bands but has never been shown experimentally (Fuhrmann et al. 2004; Yamanaka et al. 2008). If the aim is to prevent the short wave UV-light (280-380 nm) from entering the cell, diatom walls with a periodicity of holes of the order of 200-250 nm may be expected to do this while allowing visible light to pass through. However, calculations show that the refractive index contrast between silica (1.45) and either water (1.33) or air (1) together with periodicity, symmetry and 
polarization is not enough to form a full PBG in the frustule. Furthermore, the refractive index contrast between water and the frustule in natural environment of diatoms is also too low for efficient Bragg scattering but the periodic structure is still shown to have a strong absorption in the blue spectral region (Fuhrmann et al. 2004; Yamanaka et al. 2008). When a cleaned frustule is illuminated in air, the refractive index contrast is large enough for efficient Bragg scattering and at least partial photonic band gaps occur. This is seen in transmission measurements and calculations where specific wavelengths are attenuated more than others (Fuhrmann et al. 2004; Yamanaka et al. 2008; Kieu et al. 2014).

In experimental measurements where the incident light strikes the frustule normal to the surface, only a weak coupling of light to the valve plane occurs and the index contrast of the periodic structure giving rise to a small effect. Furthermore, only the direct transmitted and scattered out of plane contribution of the light from the frustule is observed and not the light guided in the valve plane, making it difficult to probe the true photonic band gap structure of the frustule. If the angle of incidence is varied from normal, a wavelength dependent redirection of the light towards the cell interior is observed. This indicates a strong interaction between the light and the frustule indicating a strong effect of the periodic structure (Romann et al. 2015, Maibohm et al. 2015c). To further increase the refractive index contrast and thereby enhance the interaction effect between light and the frustule, silica can be substituted in the growth medium with high levels of the trace substances (Townley et al. 2007; Jeffryes et al, 2008; Lang et al. 2013). Due to the fact that even the trace amount of impurities may influence photonic characteristics of the frustule, cultivation conditions must be controlled to ensure reproducible products for industrial applications. Or it can be done by 3D structural preserving chemical substitution after removal of organic material in the cleaning process (Sandhage et al. 2002; Bao et al. 2009; van Eynde et al. 2013). To further quantify and understand the light-frustule interaction, its implication on biological functions of the diatom and the possible industrial applications, more advanced photonic studies have to be conducted.

\section{Tests of the effect of the frustule on UV light}

We have found that four of the studies aimed at determining potential industrial applications of diatom frustules have analyzed or modelled the effect of the frustule silica and nano-pattern on UV light, experimentally investigating a total of three centric species as well as performing simulations. In a study on the optical properties of the centric diatom Arachnoidiscus sp., Ferrera et al. (2014) simulated the focusing effect of a frustule in air on UV-light of $300 \mathrm{~nm}$ and found that the focusing spots at this wavelength started ca. $900 \mu \mathrm{m}$ from the valve, in contrast to focusing spots of PAR light $(640 \mathrm{~nm})$, which started at ca. $200 \mu \mathrm{m}$. They also measured transmittance intensity profile at UVB and found the spot intensity low and distance far from the valve. In a previous study (on Coscinodiscus wailesii; De Tomassi et al. 2010) they showed by simulation that in water or cytoplasm, the focusing spots for PAR would be closer to the valve. De Tomassi et al. (2010) further tested the effect of a valve of Coscinodiscus wailesii on light at $280 \mathrm{~nm}$, and showed that, in contrast to light at PAR wavelengths and above $(532 \mathrm{~nm}, 633 \mathrm{~nm} \& 1000 \mathrm{~nm})$, the valve formed no focusing spots at the tested UV wavelength. Goswami et al. (2010) studied UV-luminescence properties of Cyclotella meneghiniana. In a UV-visible spectroscopy analysis of a single valve they found peak absorbance at $274 \mathrm{~nm}$. De Stefano et al (2007b) simulated UV shielding properties of pennate and centric diatoms by digitalizing scanning electron micrographs of two different frustules (from Thallassiosira rotula or Coscinodiscus wailesii and Cocconeis scutellum). Davidson et al. (1994) studied the effect of UV-B irradiation on growth and survival of six different Antarctic diatoms (Nitzschia lecointei, N. curta, Proboscis alata, 
Thallasiosira tumida, Odentella weisflogii, Chaetoceros simplex). Their focus was thus on the biology of the diatoms (see discussion above) rather than on potential industrial applications; however, one of the parameters which they analyzed was absorption spectra of the rinsed valves. They found that generally for all six species absorbance fell along the spectrum 250-800 nm. They calculated that, of total UV-B absorbance, ca. $20 \%$ was due to the frustule. This could, however, be due strictly to the material properties of the siliceous frustule and not to the pore structure. Most of these studies were done on cleaned frustules in air where the index contrast is greater that in water and therefore there is potential for stronger Bragg-scattering. Therefore, as discussed previously, it can be difficult to extrapolate these results to UV-protection for live diatoms in a watery environment.

\section{Tests of UV and PAR spectra of single frustules and layers of frustules and whole cells}

Experiments aimed at testing, for potential applications, methods for coating a surface with both rinsed frustules and cells dried with cell content were carried out to explore if the transparency was different for UV and visible wavelengths when diatoms were arbitrarily dried onto a glass plate (Fig. 3).

Light transmission was measured for two species of Coscinodiscus: C. granii and C. concinnus. Both dried intact diatoms with cell contents (dead, but with remnants of cell contents) and diatom valves rinsed of organic material were used. The diatoms were dripped onto a UV-transparent quartz silica microscope glass plate and dried at room temperature. The process was repeated several times to increase the concentration. In spite of this, we did not always achieve a high degree of coverage on the glass plate. Transparency spectra were measured using a Shimadzu UV-2600 spectrometer with build-in light sources and integrating sphere. Microscope pictures were taken using an Olympus GX41 light microscope. All measurements were repeated at least twice.

All samples had the highest transmission for the longest wavelengths and the lowest in the short wave UVspectrum as shown in Fig. 4. For rinsed dried frustules of $C$. concinnus the transmittance was reduced from ca. $67 \%$ to ca. $60 \%$ in the visible part of the spectrum from 700-400 nm. In the UV-B region (from 320-280 $\mathrm{nm}$ ) the reduction was from ca. $57 \%$ to ca. $53 \%$, i.e. the slope of the transmittance reduction was steeper in the UV-B region. A similar tendency was seen for $C$. granii, but the concentration of frustules was low and therefore the signal was less pronounced. For the dried diatoms with cell contents, the reduction in transparency is steeper and starts at $500 \mathrm{~nm}$. For C. granii, the reduction within the UV-A and UV-B spectrum $(400-280 \mathrm{~nm}$ ) is from 14 to $3 \%$. For $C$. concinnus, the reduction in the UV-spectrum is from 24 to $9 \%$. The transmission varied for the different samples depending on the concentration of the diatoms. For the rinsed diatom frustules the concentration varied between 45 and $85 \%$ and for the dried living diatoms it was $85-95 \%$ as shown in table 1 and illustrated in Fig. 3.

These preliminary results indicate that the valves are more transparent to light in the visible spectrum than in the UV spectrum, or in other words that the valves filter some of the UV light. This tendency becomes more pronounced the shorter the wavelength. For the cleaned valves, the filtering effect in the UV spectrum is seemingly rather small (below $10 \%$ ). However, this effect is likely to become larger if a complete coverage is achieved. In the measured samples only about $45-95 \%$ of the surface area was covered. To estimate the size of the expected spectral transmission for a complete coverage the data was normalized to the degree of coverage on the quartz microscope glass by multiplying with the found coverage percentage. The resulting curves in Fig. 5 show that transparency is higher for $C$. concinnus 
compared to $C$. granii for cleaned frustules and for diatoms dried with content. $C$. concinnus also has a relatively lower transparence in the UV-area. The transparency level for $C$. granii was 30-40\% (lowest for the shortest wavelengths) which was similar to the transmission observed through a single valve dropcasted on quartz (Fig. 6). The light beam was in this case masked with a pinhole to only allow light through a single frustule as shown in Fig. 1 a.

For many potential industrial applications it will be necessary to incorporate the diatoms into some kind of a matrix, e.g. paint or creme. This raises questions of how to achieve this, how high a degree of coverage is necessary for the different applications and whether the layer must be uniform and/or flat.

For the diatoms dried intact with cell content, a much more pronounced filtering can be observed. For $C$. granii only $3 \%$ of short wave UV-B at $280 \mathrm{~nm}$ is allowed through the sample in contrast to the $28 \%$ transmittance for red $700 \mathrm{~nm}$ light. In addition to the presence of cell contents, another difference between the two treatments is that in the case of the diatoms dried intact with cell contents, the frustule is intact with the two valves still together. This means that the light will always strike the side of the valve facing to the outside of the cell, and as mentioned previously, there appear to be differences in the photonic properties depending on which side of the valve is facing towards the light.

The tendency in these findings is in concordance with the findings by Noyes and colleagues (2008). They measured light transparency in the diatom C. wailesii and found approximately $80 \%$ for red light (633nm), $30 \%$ for green light $(543 \mathrm{~nm})$ and $20 \%$ for blue light $(472 \mathrm{~nm})$. They explain the varying degree of transparency with diffraction in the hole structure and point out that it is the large holes on the inside of the valve that are responsible for the diffraction. Similarly, as stated previously, Goswami et al. (2010) found peak absorbance of the frustule of Cyclotella meneghiniana at $274 \mathrm{~nm}$ and Davidson et al. (1994) found that the frustules of six different species accounted for ca. $20 \%$ of the total UV absorbance.

\section{Summary/Conclusions}

Our overall conclusion is that, while only a few species have been tested so far, the research into the role of diatom frustules in UV protection show great potential, both with regard to diatom biology and potential applications.

- Less than ten diatom species have been tested for effects of the frustule on UV light.

- Studies show that the frustule accounts for up to $20 \%$ reflectance/absorbance in the UV spectrum

- Light focusing distance depends on the wavelength, with longer distances for UV light. This could, however, be very species dependent, because of the differences in periodic structures between species.

- There are two general approaches to modeling photonic effects of diatom frustules. One considers the transmission of light through the plane of the valve with light passing through the holes, and the silica walls more or less opaque. The other considers the propagation of light in the plane of the valve and focusses on the periodic structure of the larger holes.

- Photoluminescence effects are seen when illuminating frustules with UV light. These are strongest under vacuum conditions. 
- The ability to completely exclude light of certain wavelengths (PBGs) depends on the refractive index between the frustule and the matrix as well as the periodicity of the nanostructure. So far complete PGBs have not been experimentally shown in diatoms.

- Living diatoms have a more variable response to UV light than other groups of algae - this could be due to differences in UV properties of the frustule

- Important elements to consider for UV-mediating effects are: the periodicity of the large holes (areolae), the refractive contrast between the frustule and the medium, the orientation of the valves, the degree of coverage of a layer of frustules. The small holes (in the cribrum; see figure 1) and central area appear to be less important.

\section{Acknowledgements}

This work was funded by The Danish Research Council (project ALPHA 12-127569). Sandra Walby helped with laboratory work and Jacob Snebjørn Brøgger Kristensen did preliminary studies on transmission through a spin-coated layer of frustules. Tomas Benzon helped with graphics in figure 2. Three anonymous eviewers are thanked for their comments that helped improve the manuscript.

\section{References}

1. Armbrust EV (2009) The life of diatoms in the world's oceans. Nature 459: 185-192

2. Bao Z, Ernst EM. Yoo S, Sandhage KH (2009) Syntheses of Porous Self-Supporting Metal-Nanoparticle Assemblies with 3D Morphologies Inherited from Biosilica Templates (Diatom Frustules). Adv Mater 21: 474-478

3. Bozarth A, Maier U-G, Zauner S (2009) Diatoms in biotechnology: modern tools and applications. Appl Microbiol Biotechnol 82:195-201

4. Buma AGJ, van Hannen EJ, Veldhuis MJW, Roza L, Gieskes WWC (1995) Monitoring UV-B induced DNA damage in individual diatom cells by immunofluorescent thymine dimer detection. J Phycol 31:314321

5. Buma AGJ, Zemmelink HJ, Sjollema K, Gieskes WWC (1996) UVB radiation modifies protein and photosynthetic pigment content, volume and ultrastructure of marine diatoms. Mar Ecol Prog Ser 142:47-54

6. Butcher KSA, Ferris JM Phillips MR. (2003) Photoluminescence and cathodoluminescence studies of diatoms - nature's own nano-porous silica structures. In: Cashion J, Finlayson T, Paganin D, Smith A, Troup G(Eds.) Proceedings of the 27th A and NZ Condensed Matter and Materials Meeting, 4-7 February, Charles Sturt University, Wagga Wagga, NSW, p. 51

7. Butcher KSA, Ferris JM, Phillips MR, Wintrebert-Fouquet $M$, Jong Wah J W, Jovanovic N, Vyverman W, Chepurnov VA (2005) A luminescence study of porous diatoms. Mater Sci Eng C25: 658-663

8. Coleman EA (2011) Polymer additives. In: Kutz M (ed) Applied Plastics Engineering Handbook, William Andrew, pp. 419-428. doi:10.1016/b978-1-4377-3514-7.10021-2

9. Cullen JJ, Lesser MP (1991) Inhibition of photosynthesis by ultraviolet-radiation as a function of dose and dosage rate - results for a marine diatom. Mar Biol 111:183-190.

10. Cullis AG, Canham LT, Calcott PDJ (1997) The structural and luminescence properties of porous silicon. J Appl Physics 82:909

11. Davidson AT, Bramich D, Marchant HJ, McMinn A (1994) Effects of UV-B irradiation on growth and survival of Antarctic marine diatoms. Mar Biol 199: 507-515

12. Delen N, Hooker B (1998) Free-space beam propagation between arbitrarily oriented planes based on full diffraction theory: a fast Fourier transform approach. J Opt Soc Am A 15: 857-867 
13. Depauw FA, Rogato A, d'Alcala MR, Falciatore A (2012) Exploring the molecular basis of responses to light in marine diatoms. J Exp Bot 63: 1575-1591

14. Döhler G (1995) Impact of UV-A and UV-B irradiance on the patterns of pigments and N-15ammonium assimilation of the tropical marine diatom Bellerochea yucatanensis. Bot Mar 38:513-518.

15. Döhler G (1984) Effect of UV-B Radiation on the Marine Diatoms Lauderia annulata and Thalassiosira rotula Grown in Different Salinities. Mar Biol 83:247-253

16. van Eynde E, Tytgat $T$, Smits M, Verbruggen SW, Hauchecorne B, Lenaerts S (2013) Biotemplated diatom silica-titania materials for air purification. Photochem Photobiol Sci 12: 690-695

17. Ferrara MA, Dardano P, De Stefano L, Rea I, Coppola G, Rendina I, Congestri A, Antonucci A, De Stefano M, De Tommasi E (2014) Optical Properties of Diatom Nanostructured Biosilica in Arachnoidiscus sp: Micro-Optics from Mother Nature. PLOS ONE 9 DOI: 0103750

18. Finkel ZV, Kotrc B (2010) Silica use through time: Macroevolutionary change in the morphology of the diatom frustule. Geomicrobiol J 27:596-608

19. Fuhrmann T, Landwehr S, El Rharbi-Kucki M, Sumper M (2004) Diatoms as living photonic crystals. Appl Phys B 78:257-260

20. Gale DK, Gutu T, Jiao J, Chang CH, Rorrer GL (2009) Photoluminescence Detection of Biomolecules by Antibody-Functionalized Diatom Biosilica. Adv Funct Mater 19: 926-933

21. Gijsman P (2011). Polymer Stabilization. In Kutz M (ed ) Applied Plastics Engineering Handbook, William Andrew, pp. 375-399. doi:10.1016/b978-1-4377-3514-7.10021-2

22. Guihéneuf $F$, Fouqueray $M$, Mimouni V, Ulmann L, Jacquette $B$, Tremblin G (2010) Effect of UV-stress on the fatty acid and lipid class composition in two marine microalgae Pavlova lutheri (Pavlovophyceae) and Odontella aurita (Bacillariophyceae). J Appl Phycol 22:629-638

23. Gordon R, Losic D, Tiffany MA, Nagy SS, Sterrenburg FA (2009) The Glass Menagerie: diatoms for novel applications in nanotechnology. Trends Biotechnol 27:116-27

24. Goswami B, Choudhury A, Buragohain AK (2012) Luminescence properties of a nanoporous freshwater diatom. Luminescence 27:16-19

25. Guiry MD (2012) How many species of algae are there? J Phycol 48:1057-1063

26. Hamm CE, Merkel R, Springer O, Jurkojk P, Maier C, Prechtel K, Smetacek V (2003) Architecture and material properties of diatom shells provide effective mechanical protection. Nature 421:841-843

27. Hargraves PE, Zhang J, Wang R, Shimiz Y (1993) Growth characteristics of the diatoms Pseudonitzschia pungens and $P$. fraudulenta exposed to ultraviolet radiation. Hydrobiol 269:207-212

28. Helbling EW, Chalker BE, Dunlap WC, Holm-Hansen O, Villafañe VE (1996) Photoacclimation of Antarctic marine diatoms to solar ultraviolet radiation. J Exp Mar Biol Ecol 204: 85-101

29. Hempel F, Bozarth AS, Lindenkamp N, Klingl A, Zauner S, Linne U, Steinbüchel A, Maier UG (2011) Microalgae as bioreactors for bioplastic production. Microb Cell Fact 10:81

30. Hessen DO, Frigstad H, Faerovig PJ, Wojewodzic MW, Leu E (2012) UV radiation and its effects on Puptake in arctic diatoms. J Exp Mar Biol Ecol 411:45-51

31. Holzinger A, Lütz C (2006) Algae and UV radiation: Effects on ultrastructure and related metabolic functions. Micron 37:190-207

32. Ingalls AE, Whitehead K, Bridoux MC (2010) Tinted windows: The presence of the UV absorbing compounds called mycosporine-like amino acids embedded in the frustules of marine diatoms. Geochim Cosmochim Acta 74:104-115

33. Jeffryes C, Gutu T, Jiao J, Rorrer GL (2008) Metabolic Insertion of Nanostructured $\mathrm{TiO}_{2}$ into the Patterned Biosilica of the Diatom Pinnularia sp. by a Two-Stage Bioreactor Cultivation Process, ACS nano 2:2103-2112

34. de Jonge MD, Holzner C, Baines SB, Twining BS, Ignatyev K, Diaz J, Howard DL, Legnini D, Miceli A, McNulty I, Jacobsen CJ, Vogt S (2010) Quantitative 3D elemental microtomography of Cyclotella meneghiniana at 400-nm resolution. PNAS 107: 15676-15680 
35. Johnsen, S., Sosik, H. (2004) Shedding light on the light in the ocean. Oceanus Magazine 43:

36. Karentz D, Cleaver JE, Mitchell DL (1991) Cell survival characteristics and molecular responses of Antarctic phytoplankton to ultraviolet-B radiation. J Phycol 27:326-341

37. Kieu K, Li C, Fang Y, Cohoon G, Herrera OD, Hildebrand M, Sandhage KH, Norwood RA (2014) Structure-based optical filtering by the silica microshell of the centric marine diatom Coscinodiscus wailesii. Opt Express 22:15992-15999

38. Leu E, Wangberg SA, Wulff A, Falk-Petersen S, Orbaek JB, Hessen DO (2006) Effects of changes in ambient PAR and UV radiation on the nutritional quality of an Arctic diatom (Thalassiosira antaretica var. borealis). J Exp Mar Biol Ecol 337:65-81

39. Lang Y, del Monte F, Rodriguez BJ, Dockery P, Finn DP, Pandit A (2013) Integration of $\mathrm{TiO}_{2}$ into the diatom Thalassiosira weissflogii during frustule synthesis. Sci Rep 3, article number 3205.

40. Lavoie M, Raven JA, Levassaur M (2016) Energy cost and putative benefits of cellular mechanisms modulating buoyancy in aflagellate marine phytoplankton. J Phycol 52:239-251.

41. Levithan O, Dinamarca J, Hochman G, Falkowski PG (2014) Diatoms: a fossil fuel of the future. Trends Biotechnol 32:117-124

42. Litchman E, Neale PJ (2005). UV effects on photosynthesis, growth and acclimation of an estuarine diatom and cryptomonad. Mar Ecol Prog Ser 300:53-62.

43. Lohmann M, Döhler G, Huckenbeck N, Verdini S (1998) Effects of UV radiation of different wavebands on pigmentation, ${ }^{15} \mathrm{~N}$-ammonium uptake, amino acid pools and adenylate contents of marine diatoms. Mar Biol 130:501-507

44. Mazumder N, Gogoi R, Kalita RD, Ahmed GA, Buragohain AK (2010) Luminescence studies of fresh water diatom frustules. Indian J Phys 84:665-669

45. Maibohm C, Friis SMM, Ellegaard M, Rottwitt K (2015a) Interference patterns and extinction ratio of the diatom Coscinodiscus granii. Opt Express 23:DOI:10.1364/OE.23.009543

46. Maibohm C, Friis SMM, Su Y, Rottwitt K (2015b). Comparing optical properties of different species of diatoms. Proc of SPIE Vol. 9360 93600B-1

47. Maibohm C, Nielsen JH, Rottwitt K (2015c) Light interaction with nano-structured diatom frustule, from UV-A to NIR. MSR advances http://dx.doi.org/10.1557/adv.2015.15

48. Medlin LK (2002) Why silica or better yet why not silica? Speculations as to why the diatoms utilize silica as their cell wall material. Diatom Res 17:453-459

49. Milligan AJ, Morel FMM (2002) A proton buffering role for silica in diatoms. Science 297:1848-1850

50. Nahon S, Charles F, Lantoine F, Vétion G, Escoubeyrou K, Desmalades M, Pruski AM (2010) Ultraviolet radiation negatively affects growth and food quality of the pelagic diatom Skeletonema costatum. J Exp Mar Biol Ecol 383:164-170

51. Nelson DM, Treguer P, Brzezinski MA, Leynaert A, Queguiner B (1995) Production and dissolution of biogenic silica in ocean - revised global estimates, comparison with regional data and relationship to biogenic sedimentation. Global Biogeochem Cyc 9:359-372

52. Noyes J, Sumper M, Vukusic $P$ (2008) Light manipulation in a marine diatom. J Mat Res 23:3229-3235

53. Ottesen P. (2011) Processing and characterization of diatoms for light harvesting materials on solar cells. Masters thesis, Norwegian University of Science and Technology

54. Pan Z, Lerch SJL, Xu L, Li X, Chuang Y-J, Howe JY, Mahurin SM, Dai S, Hildebrand M (2014) Electronically transparent graphene replicas of diatoms: a new technique for the investigation of frustule morphology. Sci Rep 4: 6117

55. Parker AR, Townley HE (2007) Biomimetics of photonic nanostructures. Nature Nanotechnol 2: 347-53

56. Parkinson J, Gordon R (1999) Beyond micromachining: the potential of diatoms. Trends Biotechnol 17: 190-196

57. Raven JA (1983) The transport and function of silicon in plants. Biol Rev 58:179-207 
58. Raven JA, Waite AM (2004) The evolution of silicification in diatoms: inescapable sinking and sinking as escape? New Phytol 162:45-61

59. Rech M, Mouget JL, Morant-Manceau A, Rosa P, Tremblin G (2005) Long-term acclimation to UV radiation: effects on growth, photosynthesis and carbonic anhydrase activity in marine diatoms. Bot Mar 48:407-420

60. Reizopoulou S, Santas P, Danielidis D, Hader DP, Santas R (2000) UV effects on invertebrate and diatom assemblages of Greece. J Photochem Photobiol B 56:172-180

61. Rijstenbil JW (2005) UV- and salinity-induced oxidative effects in the marine diatom Cylindrotheca closterium during simulated emersion. Mar Biol 147:1063-1073

62. Romann J, Valmalette J-C, Røyset A, Einarsrud M-A (2015) Optical properties of single diatom frustule revealed by confocal microspectroscopy. Opt Lett 40:740-3

63. Sandhage KH, Dickerson MB, Huseman PM, Caranna MA, Clifton JD, Bull TA, Heibel TJ, Overton WR, Schoenwaelder MEA (2002) Novel, Bioclastic Route to Self-Assembled, 3D, Chemically Tailored Meso/Nanostructures: Shape-Preserving Reactive Conversion of Biosilica (Diatom) Microshells. Adv Mat 14: 429-433

64. Scholz B, Rua A, Liebezeit G (2014) Effects of UV radiation on five marine microphytobenthic Wadden sea diatoms isolated from the Solthorn tidal flat (Lower Saxony, southern North Sea) - Part I: growth and antioxidative defence strategies. Eur J Phycol 49: 68-82

65. De Stefano L, Rea I, Rendina I, De Stefano M, Moretti L (2007a) Lens less light focusing with the centric marine diatom Coscinodiscus wailesii. Opt Expr 15:18082-18088

66. De Stefano L, De Stefano M, Maddalena P, Moretti L, Rea I, Mocella V, Rendina I (2007b) Playing with light in diatoms: small water organisms with a natural photonic crystal structure. Proc. SPIE 6593 Photonic Materials, Devices, and Applications II:6593-59313

67. De Stefano L, Maddalena P, Moretti L, Rea I, Rendina E, De Tommasi M, De Stefano M (2009) Nanobiosilica from marine diatoms: A brand new material for photonic applications. Superlattice Microst 46:84-89

68. De Tommasi E, Rea I, Mocella V, Moretti L, De Stefano M, Rendina I, De Stefano L (2010) Multiwavelength study of light transmitted through a single marine centric diatom. Opt Express 18:12203

69. Townley HE, Woon KL, Payne FP, White-Cooper H, Parker AP (2007) Modification of the physical and optical properties of the frustule of the diatom Coscinodiscus wailesii by nickel sulfate. J Nanotechnol 18:295101

70. Vernet M (2000) Effects of UV radiation on the physiology and ecology of marine phytoplankton. In: De Mora SJ, Demers S, Vernet M (eds) The Effects of UV Radiation in the Marine Environment, Cambridge University Press, Cambridge, pp. 237-278

71. Viji S, Anbazhagi M, Ponpandian N, Mangalaraj D, Jeyanthi S, Santhanam P, Devi, AS, Viswanathan C (2014) Diatom-Based Label-Free optical Biosensor for Biomolecules. Appl Biochem Biotechnol 174:1166-1173

72. Villafañe VE, Helbling EW, Holm-Hansen O, Chalker BE (1995) Acclimatization of Antarctic natural phytoplankton assemblages when exposed to solar ultraviolet radiation. J Plankton Res 17: 2295-2306

73. Wang Y, Pan J, Cai J, Zhang D (2012) Floating assembly of diatoms Coscinodiscus sp. microshells. Biochem Biophys Res Commun 420:1-5

74. Waring J, Underwood GJC, Baker NR (2006) Impact of elevated UV-B radiation on photosynthetic electron transport, primary productivity and carbon allocation in estuarine epipelic diatoms. Plant Cell Environ 29:521-534

75. Wu XJ, Gao G, Giordano M, Gao KS (2012) Growth and photosynthesis of a diatom grown under elevated $\mathrm{CO}_{2}$ in the presence of solar UV radiation. Fundam Appl Limnol 180:279-290

76. Wu Y, Campbell DA, Gao K (2014) Faster recovery of a diatom from UV damage under ocean acidification. J Photochem Photobiol B 140:249-254. 
77. Xu J, Gao K (2010) Use of UV-A Energy for Photosynthesis in the Red Macroalga Gracilaria lemaneiformis. Photochem Photobiol 86: 580-585

78. Yamanaka S, Yano R, Usami H, Hayashida N, Ohguchi M, Takeda H, Yoshino K (2008) Optical properties of diatom silica frustule with special reference to blue light. J Appl Phys 103:074701 


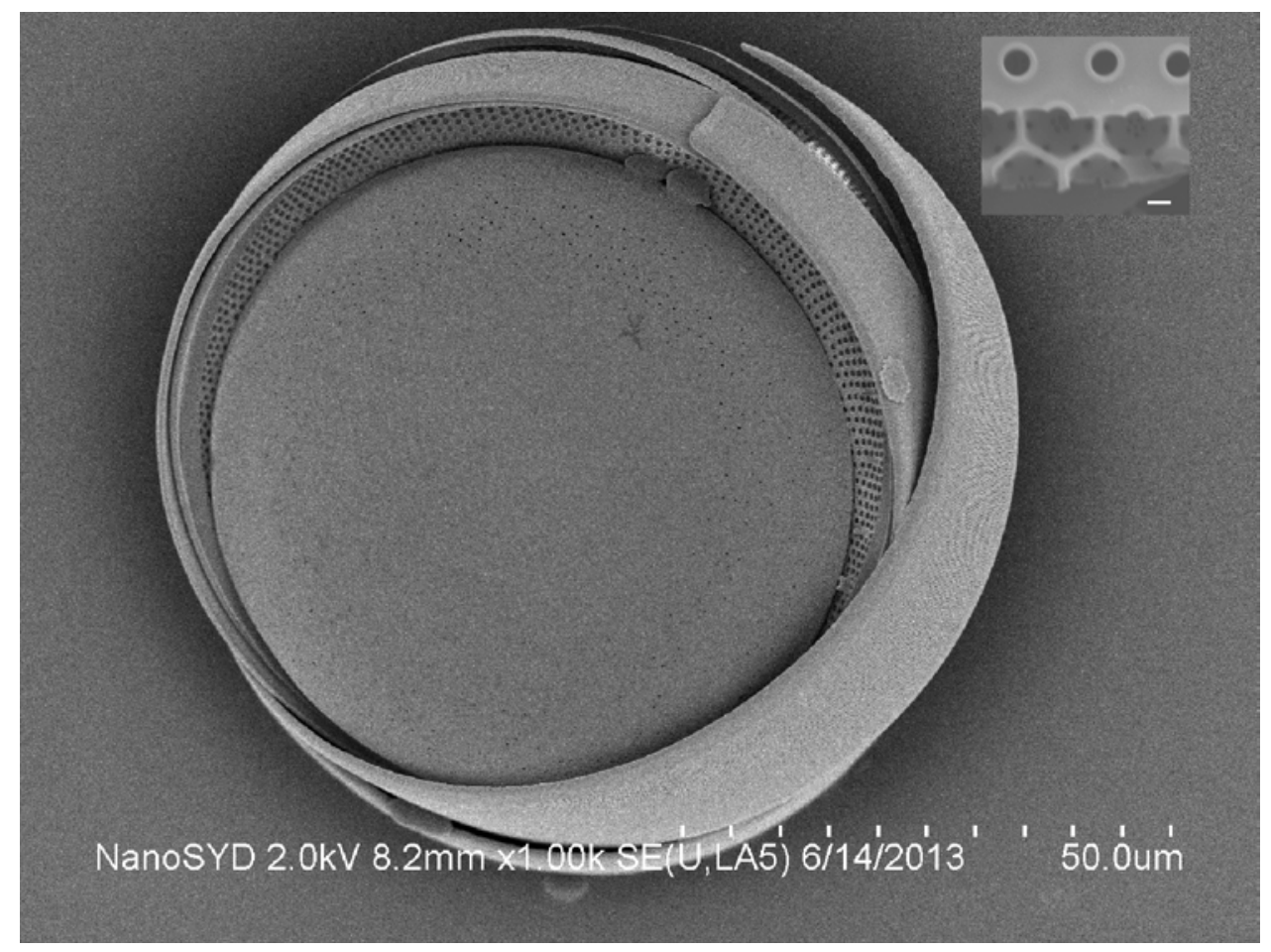

Figure 1: Scanning electron images of Coscinodiscus granii, showing a valve seen from the outside of the cell and girdle bands partly detached. Insert: Scale bar $500 \mathrm{~nm}$; small section of a diatom valve showing the 3D structure.
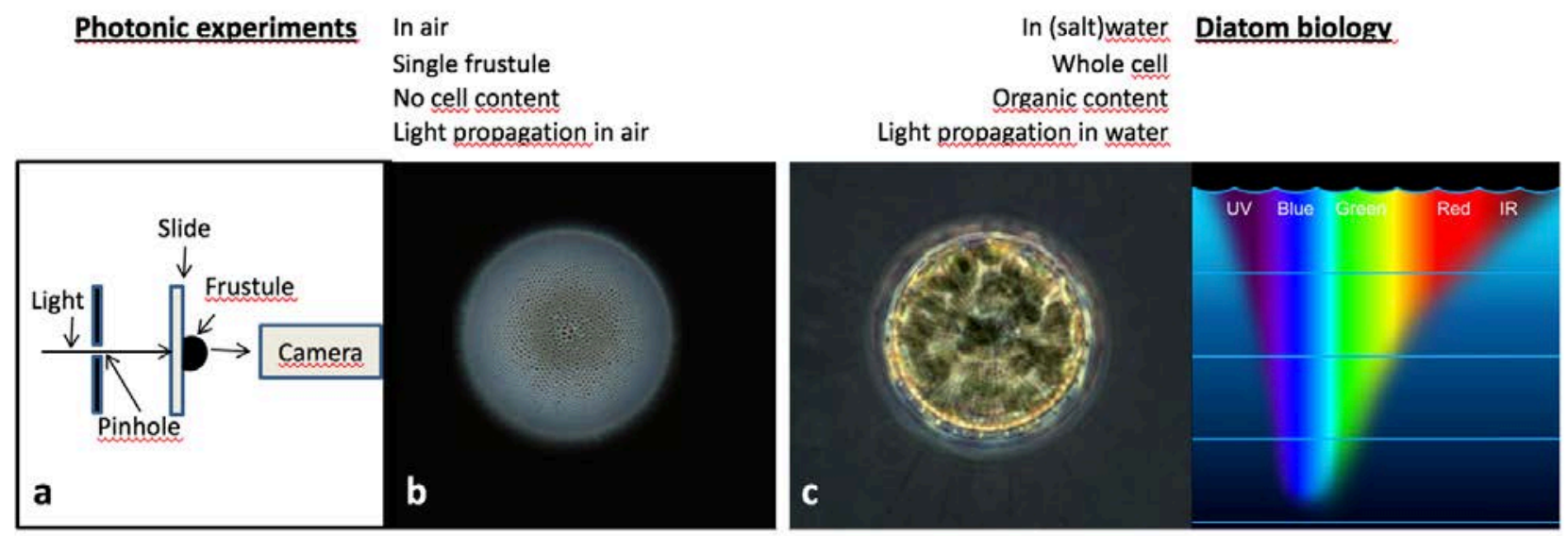

Figure 2: Overview over relevant features that differ between the diatom in its natural habitat and a rinsed diatom valve in a typical experimental photonic set-up (a). b: A diatom valve rinsed of organic material and seen under light microscope. c: A live diatom in water (light micrograph). d: A schematic of spectral changes in light through a water column 

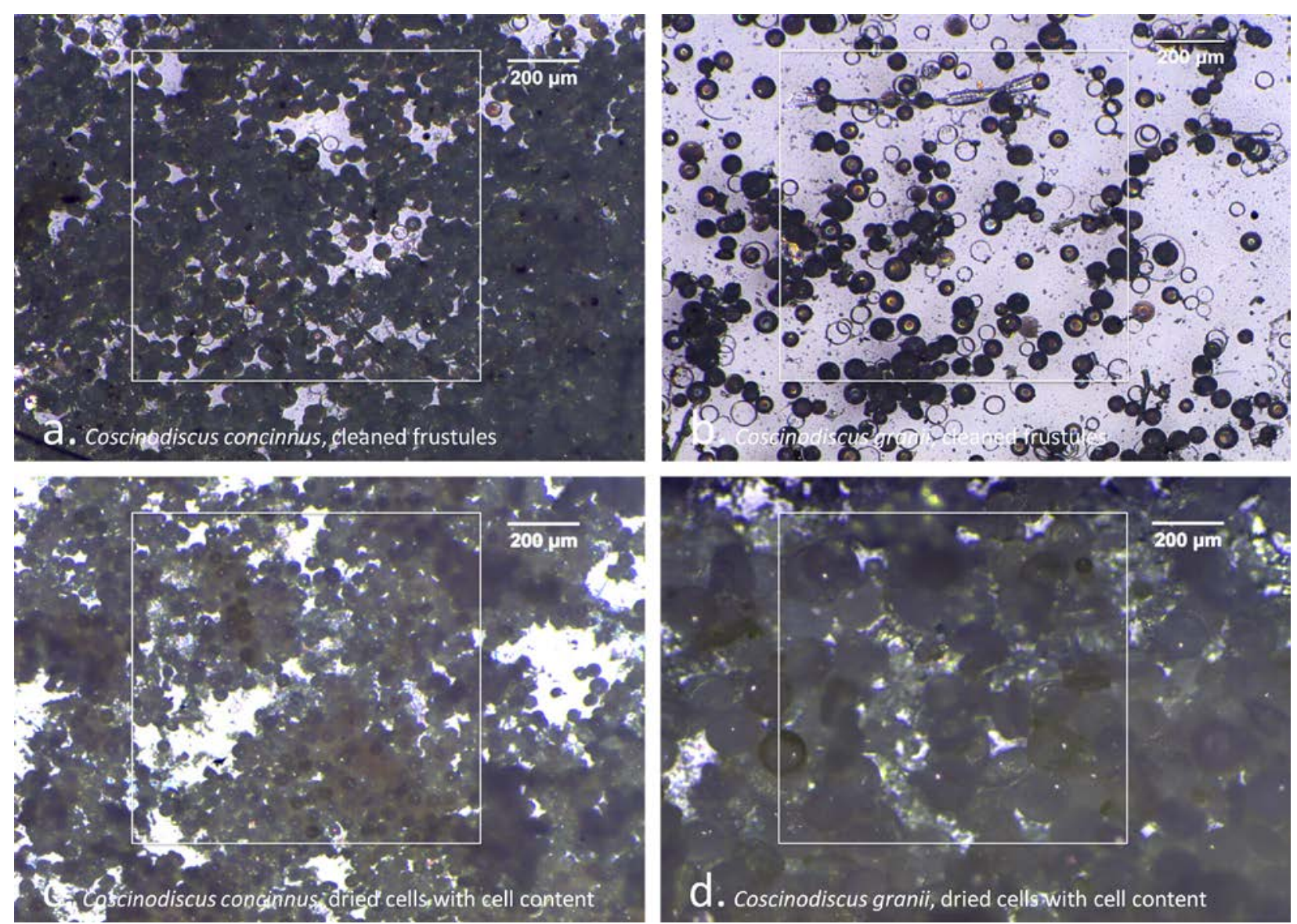

Figure 3: Light microscope pictures of dried diatoms on a UV-transparent quartz silica microscope glass plate. Scale bar $0.2 \mathrm{~mm}$. Coverage (see table 1) is estimated within the white square. a: Coscinodiscus concinnus, cleaned frustules b: $C$. granii, cleaned frustules. c: $C$. concinnus, dried cells with cell content. d: $C$. granii, dried cells with cell content. 


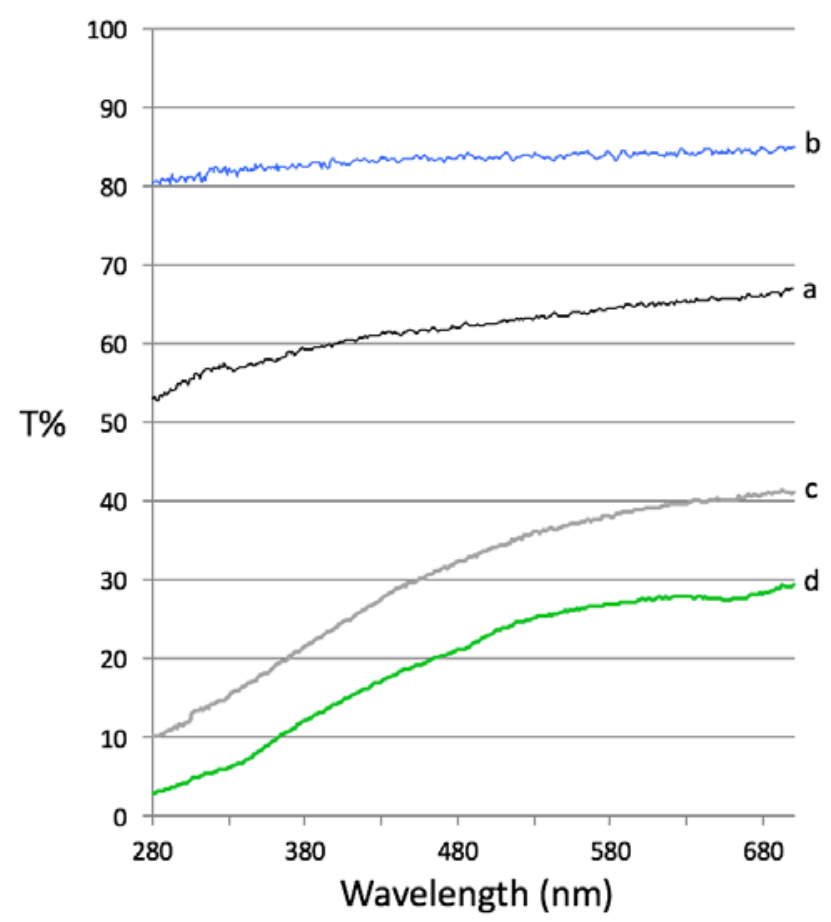

Figure 4: Transmittance spectra for a: Coscinodiscus concinnus, cleaned frustules b: $C$. granii, cleaned frustules. c: $C$. concinnus, dried cells with cell content. $\mathbf{d}$ : $C$. granii, dried cells with cell content. The reference spectrum is the UV-transparent quartz silica microscope glass plate with nothing on top of it.

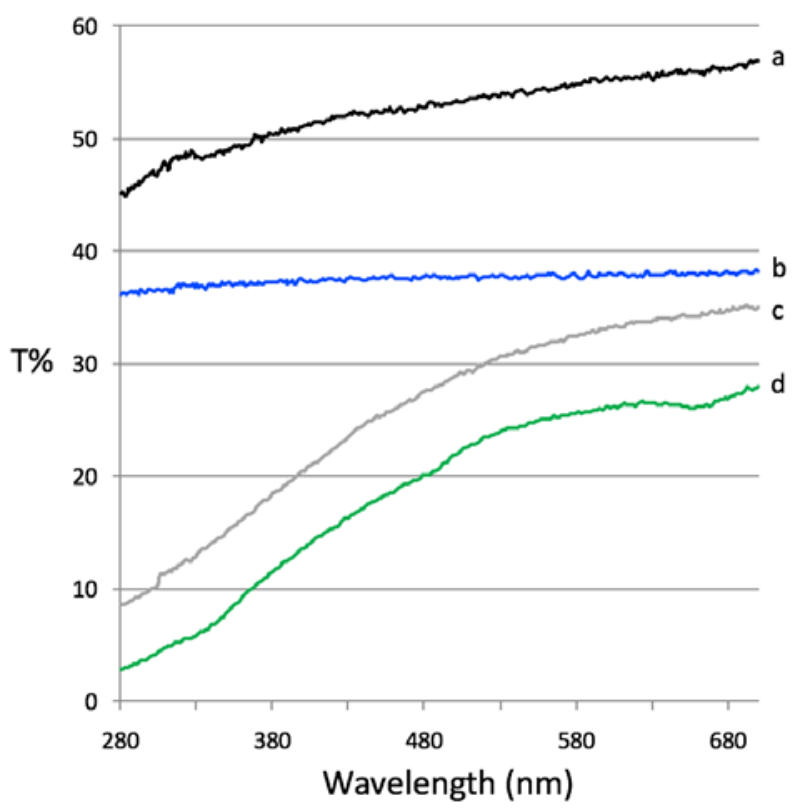

Figure 5: Transmittance spectra from Figure 4 normalized to degree of coverage on the quartz microscope glass. a: Coscinodiscus concinnus, cleaned frustules b: $\boldsymbol{C}$. granii, cleaned frustules. c: $C$. concinnus, dried cells with cell content. d: $C$. granii, dried cells with cell content. 


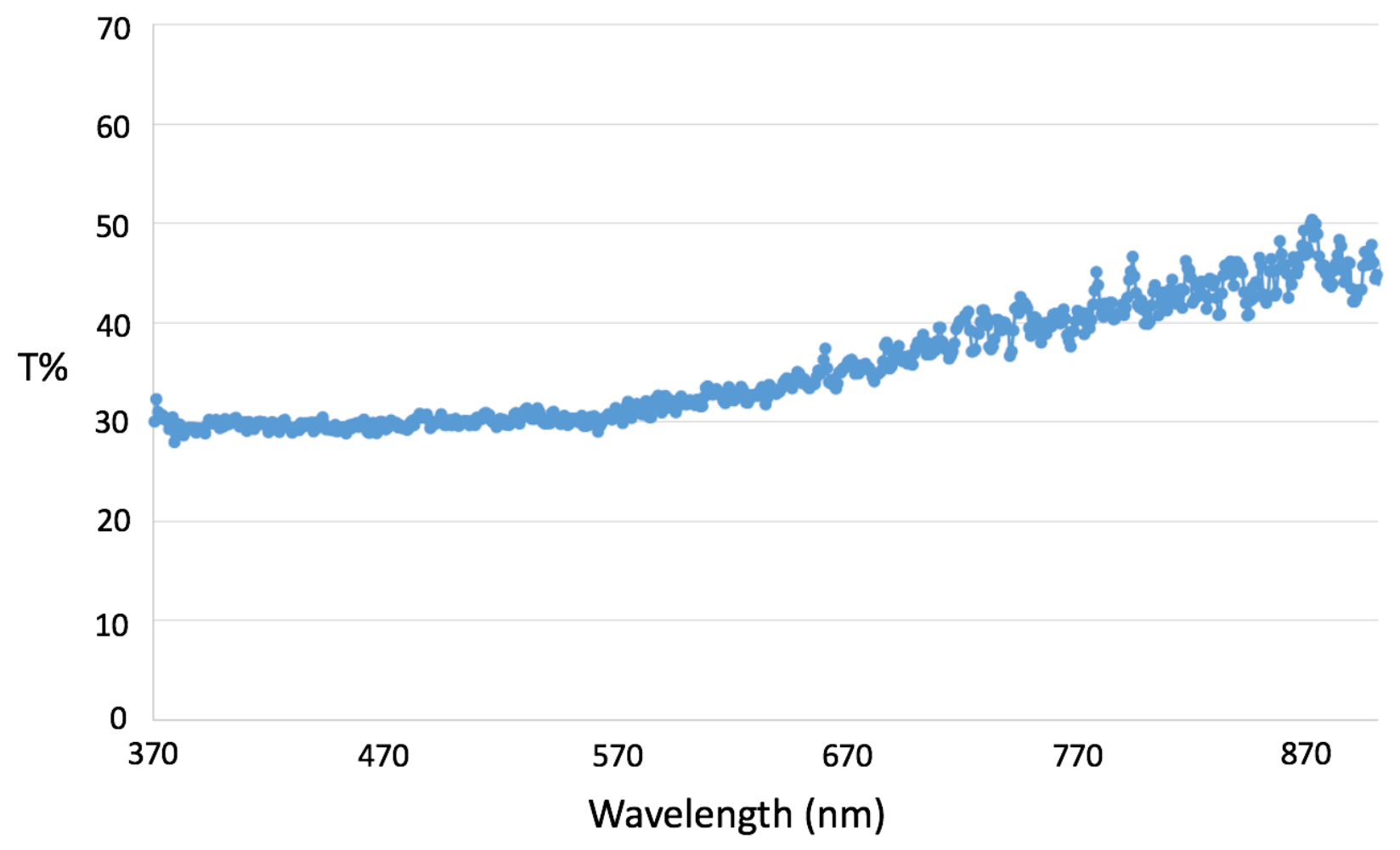

Figure 6: Transmission through a single valve of $C$. Granii normalized to the background.

Table 1: Average diatom diameter and coverage percentage for diatoms on quartz glass shown in Fig. 3.

\begin{tabular}{|l|c|c|c|}
\hline & $\begin{array}{c}\text { Approximate } \\
\text { diameter of diatom } \\
\text { valve }(\mu \mathrm{m})\end{array}$ & $\begin{array}{c}\text { Standard deviation } \\
\text { diameter of diatom }\end{array}$ & \% coverage \\
\hline 1. C concinnus cleaned & 49 & 6.09 & Ca 85 \\
\hline 2. C granii cleaned & 62 & 2.61 & Ca 45 \\
\hline $\begin{array}{l}\text { 3. C concinus dried with cell } \\
\text { content }\end{array}$ & 43 & 12.18 & Ca 95 \\
\hline $\begin{array}{l}\text { 4. C granii dried with cell } \\
\text { content }\end{array}$ & 146 & 1.71 & \\
\hline
\end{tabular}

